\title{
Evolución fisicoquímica y de las bacterias del azufre en microcosmos de diferentes sistemas acuáticos de la Región Amazonas
}

\section{Physicochemical and bacterial evolution of sulfur in microcosms of different aquatic systems in the Amazon region}

\author{
(iD) 'Jesús Rascón Barrios (iD 2Fernando Corroto de la Fuente
}

Universidad Nacional Toribio Rodríguez de Mendoza de Amazonas. Chachapoyas, Perú. Universidad Autónoma de Madrid. Madrid, España.

\section{Resumen}

El ciclo de azufre es uno de los ciclos biogeoquímicos más importantes del planeta. Sin embargo, la contaminación generada por las actividades antrópicas puede modificar este ciclo, sobre todo en los ecosistemas acuáticos, al ser más vulnerables. El principal objetivo del estudio fue crear columnas de Winogradsky a partir de agua y sedimentos de cuatro ecosistemas acuáticos en la Región Amazonas, dos lénticos y dos lóticos, estudiando los microorganismos relacionados con el ciclo del azufre que se desarrolla en cada ecosistema, y cómo están afectados. Para ello, se determinaron los gradientes fisicoquímicos generados y cómo se agrupan, tanto estos, como los ecosistemas y las columnas creadas. Se analizaron en cada ecosistema acuático y en cada columna de Winogradsky, parámetros fisicoquímicos como oxígeno disuelto (OD) sulfatos (SO4), fosfatos (PO4), nitratos (NO3), nitritos (NO2) y amonio (NH4). Las columnas de Winogradsky creadas no mostraron todos los estratos que deberían presentar. Los gradientes fisicoquímicos fueron, en general, normales, excepto el del OD en los ecosistemas lénticos, indicando una posible eutrofización. Se observó que los ecosistemas acuáticos y las columnas de Winogradsky creadas forman tres grupos muy marcados, en uno se agrupan las columnas de los ecosistemas lénticos, en otro las columnas de los lóticos y en otro todos los ecosistemas. Los parámetros de $\mathrm{SO} 4$ y PO4 forman un grupo totalmente separado del resto de variables en cuanto a la agrupación de los parámetros fisicoquímicos. Por tanto, el ciclo del azufre en los ecosistemas acuáticos estudiados de la Región Amazonas se vio afectado, principalmente, por actividades antrópicas como la agricultura y la ganadería.

Palabras clave: Columnas de Winogradsky, ciclos biogeoquímicos, lago Burlan, lago Pomacochas, río Pomacochas, quebrada El Mito.

Recibido: Febrero 2020

Aceptado: Mayo 2020

\section{Abstract}

The sulphur cycle is one of the most important biogeochemical cycles on the planet. However, pollution generated by human activities can modify this cycle, especially in aquatic ecosystems, as they are more vulnerable. The main objective of the study was to create Winogradsky columns from water and sediments of 
four aquatic ecosystems in the Amazon Region, two lentic and two lotic, studying the microorganisms related to the sulphur cycle that develops in each ecosystem, and how they are affected. To this end, the physicochemical gradients generated and how they are grouped, as well as the ecosystems and columns created, were determined. In each aquatic ecosystem and in each Winogradsky column, physicochemical parameters such as dissolved oxygen (DO) sulphates (SO4), phosphates (PO4), nitrates (NO3), nitrites (NO2) and ammonium (NH4) were analysed. The Winogradsky columns created did not show all the layers they should have. The physicochemical gradients were generally normal, except for the OD in lentiche ecosystems, indicating a possible eutrophication. It was observed that the aquatic ecosystems and the Winogradsky columns created form three very marked groups, in one the columns of the lentic ecosystems are grouped, in another the columns of the lotics and in another all the ecosystems. The SO4 and PO4 parameters form a group totally separated from the rest of the variables in terms of the grouping of the physico-chemical parameters. Therefore, the sulphur cycle in the aquatic ecosystems studied in the Amazon Region was mainly affected by anthropogenic activities such as agriculture and livestock farming.

Keywords: Winogradsky columns, biogeochemical cycles, Burlan Lake, Pomacochas Lake, Pomacochas River, El Mito Creek

\section{INTRODUCCIÓN}

El azufre es uno de los compuestos más importantes para los seres vivos, principalmente, en una gran variedad de funciones metabólicas, además de ser un elemento esencial en las proteínas (Rogan et al., 2005). Este ciclo consiste en la circulación de diversos compuestos del azufre a través del aire, suelo, agua y seres vivos. Dentro del ciclo del azufre, los compuestos más típicos son el dióxido de azufre $\left(\mathrm{SO}_{2}\right)$, el sulfato $\left(\mathrm{SO}_{4}{ }^{2-}\right)$, el azufre elemental $\left(S^{0}\right)$ y el ácido sulfhídrico $\left(\mathrm{H}_{2} \mathrm{~S}\right)$. Este último presenta un olor característico a huevos podridos (Freedman, 2018). Existen dos vías en este ciclo, la aeróbica y la anaeróbica, donde las bacterias juegan un papel fundamental, ya que a través de diferentes reacciones, transforman los compuestos del azufre (López-Pérez y Boronat-Gil, 2019).

Los ecosistemas acuáticos son muy vulnerables a la contaminación, en especial los andinos y selváticos (Blaber y Barletta, 2016). Es de gran importancia su estudio, debido a la cantidad de valores ambientales, sociales, económicos y científicos que encierran (Guerrero et al., 1991). La contaminación esta generada principalmente por actividades antropogénicas (Nogales et al., 2011), como la agricultura (Chagnon et al., 2015), la ganadería (Li et al., 2016), la deforestación o la quema de combustibles fósiles, entre otras (Goldemberg et al., 2008). Al mismo tiempo son las principales fuentes de emisión de gases de efecto invernadero (Nicoletti et al., 2015) o de desechos bioquímicos (Kolpin et al., 2002). Algunas de las consecuencias de estas emisiones son las Iluvia ácida (Nicoletti et al., 2015) o la eutrofización de los cuerpos de agua (Zamparas y Zacharias, 2014).

Algunos gases de efecto invernadero $\left(\mathrm{SO}_{2}\right)$ o desechos bioquímicos $\left(\mathrm{SO}_{4}{ }^{2-}\right)$ pueden tener efectos negativos en el ciclo biogeoquímico del azufre, los cuales tienen un papel muy importante en los ecosistemas acuáticos (Prosini et al., 2009; Bucher y Abril, 2006). Uno de estos efectos negativos es la modificación de la red trófica dentro de los ecosistemas acuáticos (Ortega y Villalba, 1986; Rabalais et al., 2014). De modo que conocer como es el ciclo del azufre en cada ecosistema acuático así como los microorganismos que participan, dan una mejor visión de los 
efectos provocados por los contaminantes (Anderson y Hariston, 1999; Galván y Rios, 2013).

Los bacterias que participan en el ciclo del azufre son un grupo muy heterogéneo (Gutierrez et al., 2007). Las que más destacan son las bacterias fotosintéticas del azufre, las cuales son muy diversas (Martínez, 2013). Cuando las condiciones en los ecosistemas acuáticos son favorables, las bacterias fotosintéticas del azufre tienen un crecimiento masivo. Ocupan toda la columna de agua o formando capas identificables a simple vista gracias a sus pigmentos fotosintéticos, con tonalidades rosa, verde, roja y púrpura (Picazo et al., 2013). Las bacterias fotosintéticas del azufre también son conocidas como bacterias fotótrofas anoxigénicas, por no producir oxígeno durante la fotosíntesis (Bacchetti De Gregoris et al., 2015). Sin embargo, la fotosíntesis de estas bacterias depende de la concentración de oxígeno, porque en su presencia se inhibe la síntesis de pigmentos fotosintéticos (Núñez-Car- dona, 2003; Sacaca, 2006). Otros factores a tener en cuenta son la cantidad y calidad de luz que reciben (Pibernat y Abella, 1994; Sanmartín et al., 2017) y la disponibilidad de donadores de electrones como el $\mathrm{H}_{2} \mathrm{~S}$ o el $\mathrm{S}^{0}$ (Uchimiya y Stone, 2009; Bacchetti De Gregoris et al., 2015).

Una columna de Winogradsky es un ecosistema en miniatura o microcosmos (Figura 1). Se puede usar como un modelo para estudiar las comunidades microbianas involucradas en el ciclo del azufre en ecosistemas acuáticos (Benoit, 2015). Esto se debe a que es un sistema complejo y autónomo de reciclaje, mantenido sólo por la energía lumínica (Moreno et al., 2012). Dentro de la columna de Winogradsky se pueden identificar diferentes microrganismos, según la coloración del estrato que se forma (Tabla 1). Con ello se puede determinar la ecología microbiana, y así conocer los organismos que participan en el ciclo del azufre en los ecosistemas acuáticos (Pagaling et al., 2014, 2017)

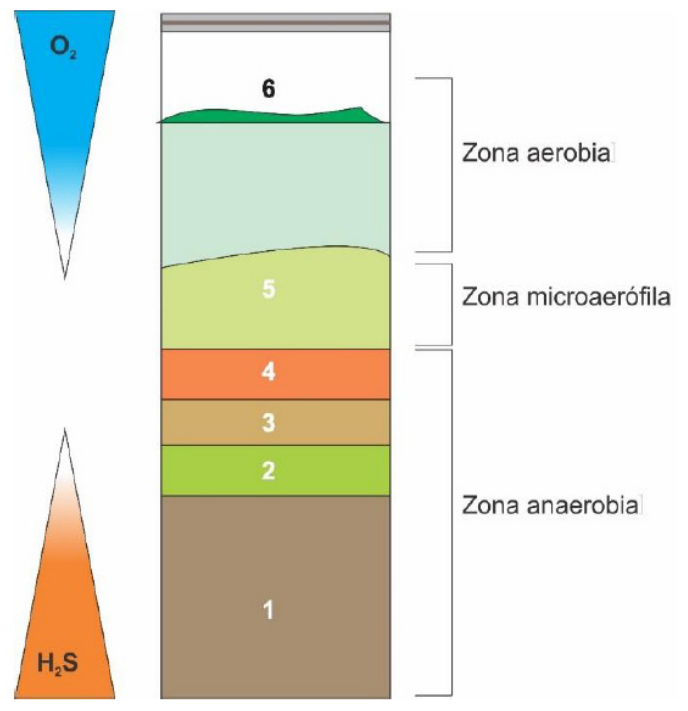

Figura 1. Esquema general de una Columna de Winogradsky indicando sus tres zonas principales con sus diferentes estratos: 1. Estrato de los organismos reductores y fermentadores (puede tener color negro Bacterias Sulfatoredutoras). 2. Estratos de Bacterias Verdes del azufre. 3. Estrato de Bacterias Púrpuras o Rojas del azufre. 4. Estrato de Bacterias Púrpuras o Rojas no del azufre. 5. Estrato de sulfo-oxidadores aeróbios y $\mathbf{6}$. Estratos de fotótrofos oxigénicos (cianobacterias). 
Tabla 1. Cuadro de identificación de potenciales microorganismos en base a la coloración de los estratos.

\begin{tabular}{cl}
\hline Color estrato columna & Organismos característicos del estrato \\
\hline Verde & Algas y Cianobacterias \\
Rojo/Marrón & Cianobacterias o Tiobacilos \\
Rojo/Púrpura & Bacterias púrpuras no del azufre \\
Blanco & Bacterias sulfo-oxidadoras \\
Rojo/Púrpura & Bacterias púrpuras del azufre \\
Verde & Bacterias verdes del azufre \\
Negro & Bacterias sulfo-reductoras o fermentadoras \\
\hline
\end{tabular}

Fuente: Moreno et al. 2012

La Región Amazonas, localizada al norte de Perú, posee una gran variedad de ecosistemas lénticos y lóticos, desde andinos hasta selváticos. Sin embargo, no hay una gran cantidad de estudios sobre ellos, y menos sobre los ecosistemas bacterianos relacionados con el ciclo del azufre. Por ello en esta investigación se construyen columnas de Winogradsky de cuatro ecosistemas acuáticos diferentes. Gracias a ellos, se determinan los gradientes fisicoquímicos generados en cada columna, y cómo se relacionan los parámetros fisicoquímicos, así como los ecosistemas acuáticos y las columnas creadas. Asimismo, se determinan que tipo de microorganismos se desarroIlan en cada columna de Winogradsky, y, por tanto, en cada ecosistema acuático. Con ello se busca conocer el ciclo del azufre en cada ecosistema y cómo está de afectado por la contaminación.

\section{MATERIALES Y MÉTODOS Recolección de muestras}

Los muestreos de agua y sedimento se realizaron en el mes de Agosto de 2017, durante la estación seca. Las muestras se obtuvieron de cuatro ecosistemas diferentes localizados en la Región Amazonas. Estos ecosistemas fueron el lago Burlan, el lago Pomacochas, el río Pomacochas y la quebrada El Mito.

El lago Burlan se encuentra en el distrito de Bagua Grande, en la provincia de Utcubamba. Es un lago de origen artificial como consecuen- cia de los aportes hídricos de los desagües de los arrozales colindantes (Sánchez-Vasquez, 2018). Pertenece a la Región Hidrográfica del Amazonas, dentro de la cuenca del río Marañón, situándose a una altitud de 420 m.s.n.m., y posee una superficie de 45,93 hectáreas y una profundidad máxima de 9 metros. Tiene una temperatura media anual de $25,9{ }^{\circ} \mathrm{C}$ y una precipitación media anual de 50,95 mm (SENAMHI, 2020). La actividad principal en la zona es la agricultura, sobre todo de arroz. Dentro del lago la actividad más desarrollada es el turismo, mediante el paseo en botes y motos acuáticas y varios restaurantes, en la zona sur del lago (Alva-Cruz, 2010).

El lago Pomacochas se localiza en el distrito de Florida, en la provincia de Bongará. Tiene un origen tectónico, como resultado del hundimiento y levantamiento del terreno (Wetzel, 2001). Su principal aporte de agua es a través de las precipitaciones. Está dentro de la Región Hidrográfica del Amazonas, dentro de la cuenca del río Marañón, a una altitud de 2233 m.s.n.m., con una superficie de 422 hectáreas y 75.50 metros de profundidad máxima. Tiene una temperatura media de $20,9^{\circ} \mathrm{C}$ y una precipitación media anual de 47.98 mm (SENAMHI, 2020). La principal actividad económica de la zona es la ganadera, en fundos de explotación extensiva (Oliva et al., 2015). En el lago, la actividad acuícola es importante, por la pesca tradicional de pejerrey y plateados (Barboza-Castillo et al., 2014). 
El río Pomacochas se encuentra en el distrito de Leimebamba, en la provincia de Chachapoyas. Pertenece a la Región Hidrográfica del Amazonas, dentro de la cuenca del río Utcubamba, afluente del río Marañón. Tiene un gradiente altitudinal entre 3523 m.s.n.m. y 2229 m.s.n.m., donde predominan los bosques nubosos, los pajonales y los pastizales deforestados. La zona tiene una temperatura media anual de $15.3^{\circ} \mathrm{C}$ y una precipitación media anual de 64.32 mm (SENAMHI, 2020). La principal actividad es la ganadería extensiva junto a la agricultura de cultivos andinos como papa, frejoles y maíz (Briceño et al., 2020).

La quebrada El Mito se encuentra en el distrito de San Nicolás, en la provincia de Rodríguez de Mendoza. Pertenece a la Región Hidrográfica del Atlántico, dentro de la cuenca del río Huayabamba, afluente del río Huallaga. Posee un gradiente altitudinal entre 1517 m.s.n.m. y 1441 m.s.n.m., destacando por sus bosques húmedos tropicales. La temperatura media anual es de $21.3^{\circ} \mathrm{C}$ y la precipitación media anual es de 97.68 mm (SENAMHI, 2020). La actividad económica más representativa de la zona es la producción de café (Puscan et al., 2018).

En cada ecosistema acuático se establecieron dos puntos de muestreo siguiendo la metodología establecida por Karlov et al. (2017). Los puntos fueron señalados en campo, mediante un receptor de Posicionamiento Global (GPS), marca Garmin, Modelo Oregon 650.

Para elaborar las columnas de Winogradsky se precisaron dos tipos de muestras: de agua y de sedimento. Las muestras de agua se recolectaron en recipientes de plástico de un litro para su posterior análisis fisicoquímico en laboratorio. Para la toma de muestras de agua se siguió el protocolo nacional para el monitoreo de la calidad de los recursos hídricos superficiales, establecido por la ANA (2016). Las muestras de sedimento se recolectaron en recipientes de plástico tipo "tupperware" de un litro. Para la toma de muestras de sedimentos se siguieron las recomendaciones de Karlov et al. (2017) y Zakharenko et al.
(2015). Una vez establecidas las columnas de Winogradsky, se tomaron muestras de agua de la parte superior e inferior de cada una, una vez al mes, durante la duración del estudio.

\section{Parámetros fisicoquímicos}

Los análisis de in situ y de laboratorio, se realizaron de acuerdo con APHA, AWWA y WEF (2017). Estos parámetros fueron oxígeno disuelto (OD) usando un equipo multiparamétrico marca SI Analytics, modelo HandyLab 680. El resto de parámetros medidos fueron sulfatos $\left(\mathrm{SO}_{4}\right)$, fosfatos $\left(\mathrm{PO}_{4}\right)$, nitratos $\left(\mathrm{NO}_{3}\right)$, nitritos $\left(\mathrm{NO}_{2}\right)$ y amonio $\left(\mathrm{NH}_{4}\right)$, usando un espectrofotómetro de absorción UV-VIS, marca Thermo Scientific, Modelo Genesys 10 S V-VIS.

\section{Construcción de las columnas de Wino- gradsky}

Para la construcción de las columnas de Winogradsky se siguieron las metodologías propuestas por Grau et al. (1991) y Pagaling et al. (2017). En un primer momento se mezclaron las dos muestras de sedimento de cada ecosistema acuático. En cuencos de porcelana se adicionaron $500 \mathrm{ml}$ de cada mezcla de sedimento, $4 \mathrm{~g}$ de sulfato de calcio $\left(\mathrm{CaSO}_{4}\right)$ como fuente de sulfatos, y $4 \mathrm{~g}$ de carbonato de calcio $\left(\mathrm{CaCO}_{3}\right)$ como agente tamponador de $\mathrm{pH}$. Luego se colocaron $400 \mathrm{ml}$ de cada mezcla en probetas de vidrio de $1000 \mathrm{ml}$ y se agregó agua de cada ecosistema acuático hasta $3 \mathrm{~cm}$ del borde. Cada columna se dejó decantar durante tres días. Pasado ese tiempo se agregó, como fuente de carbono y energía, una hoja de papel filtro de $190 \mu \mathrm{m}$ de grosor y 125 mm de diámetro, finamente picado y con cuidado de que no quedaran burbujas de aire. Se cubrió la boca de cada probeta con parafilm para evitar tanto la evaporación como la entrada de polvo. Posteriormente, se cubrieron las probetas con papel aluminio y se colocaron en una estufa a $30^{\circ} \mathrm{C}$ durante una semana. Tras ese tiempo las probetas se incubaron a una temperatura ambiente de $19,8^{\circ} \mathrm{C}$. Todas las columnas se expusieron a la luz continua de dos bombillas con filamento de tungsteno y $100 \mathrm{~W}$ de potencia durante tres meses. 


\section{Análisis de datos}

En primer lugar, se determinaron los gradientes fisicoquímicos generados en cada columna mediante gráficos elaborados por Excel. Se crearon dos dendrogramas utilizando la correlación de Pearson y aplicando el método de agrupación por ligamento promedio, uno para agrupar los ecosistemas acuáticos y sus respectivas columnas, y otro para agrupar los parámetros fisicoquímicos. Además, para determinar las diferencias significativas de los parámetros fisicoquímicos según los ambientes acuáticos, se realizó una ANOVA. Todos los análisis estadísticos se realizaron a un nivel de significancia de $p<0.05$, a través del software estadístico $R(R$ Core Team 2020). Por último, se identificaron los microorganismos generados en cada columna a través de una revisión bibliográfica, usando las coloraciones generadas como guía.

\section{RESULTADOS Y DISCUSIÓN Gradientes fisicoquímicos de las columnas de Winogradsky}

Cuando se forma una columna de Winogradsky, en la parte superior se desarrollan algas y cianobacterias que producen oxígeno, estableciendo una zona aeróbica. Por otro lado, en el fondo de la columna se desarrollan bacterias reductoras del sulfato que producen sulfuro, el cual ayuda al desarrollo de las bacterias rojas y verdes del azufre. De este modo, se establecen dos gra- dientes en la columna, uno de oxígeno y otro de sulfuros (Babcsányi et al., 2017).

En la columna creada con agua y sedimento del lago Burlan, el gradiente de OD generado es contrario al esperado, al tener mayor concentración de oxígeno en la parte inferior (Figura 2A). La modificación del gradiente de OD se da cuando el desarrollo de las cianobacterias en la parte superior de los sedimentos es mayor al de las algas y cianobacterias de la parte superior del agua (Madigan et al., 2019). Por otro lado, el gradiente de $\mathrm{SO}_{4}$ generado es el esperado en las columnas de Winogradsky (Figura 2B). Tanto $\mathrm{PO}_{4}$ como $\mathrm{NO}_{3}$ tienen un gradiente de mayor a menor concentración desde la zona superior a la inferior (Figura 2C, 2D y 2E). Los gradientes de $\mathrm{PO}_{4}$ y $\mathrm{NO}_{3}$ indican que el desarrollo de organismos fotoautótrofos es mayor en la zona inferior de la columna, en forma de tapetes bacterianos encima de los sedimentos (Giraldo, 2012). No obstante, los gradientes de $\mathrm{NO}_{2}$ y $\mathrm{NH}_{4}$ son ambiguos (Figura 2F). Esto se debe a que ambos son desechos de los microorganismos, y por tanto tendría que haber mayor concentración de estos en la zona inferior (Leiva et al., 2017). Este comportamiento con los compuestos nitrogenados también se observó en columnas creadas con sedimentos y aguas de sistemas de recirculación de Costa Rica (Jimenez-Montealegre et al., 2015).
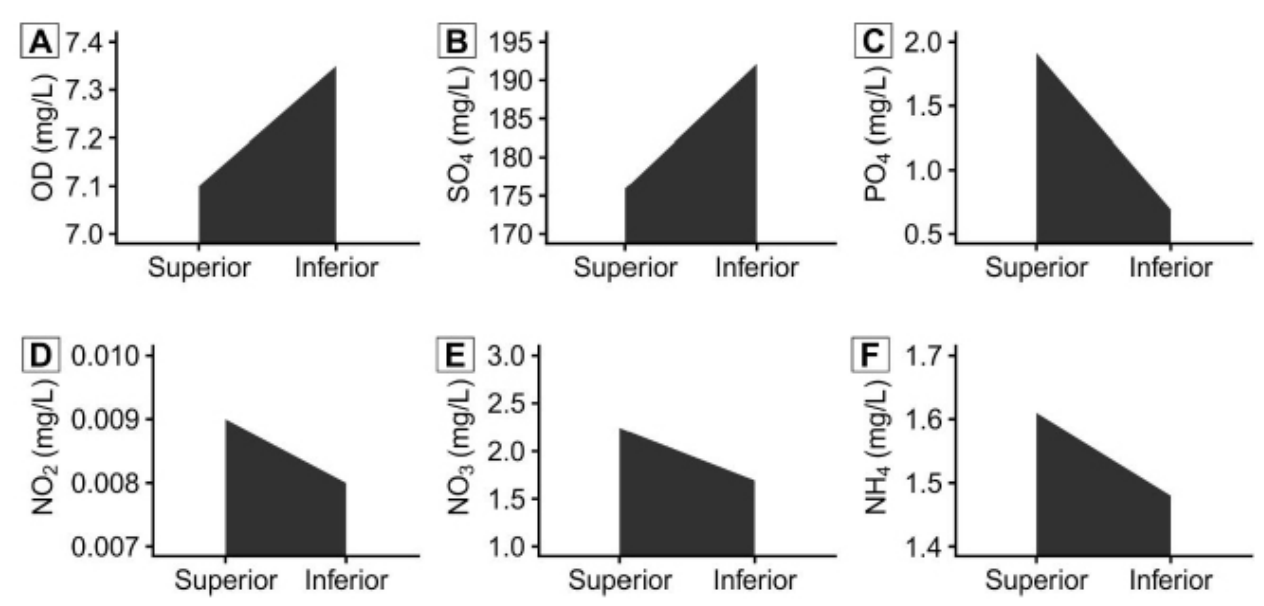

Figura 2. Gradientes fisicoquímicos generados en la columna de Winogradsky del lago Burlan. (A) OD, (B) $\mathrm{SO}_{4^{\prime}}$ (C) $\mathrm{PO}_{4^{\prime}}$ (D) $\mathrm{NO}_{2^{\prime}}$ (E) $\mathrm{NO}_{3^{\prime}}$ (F) $\mathrm{NH}_{4^{\prime}}$. 
En la columna creada con agua y sedimento del lago Pomacochas, los gradientes de OD, $\mathrm{SO}_{4}$ y $\mathrm{PO}_{4}$ son similares a los de la columna del lago Burlan (Figura 3A, 3B y 3C). Sin embargo, $\mathrm{NO}_{2}$ se mantiene constante en toda la columna, mientras que $\mathrm{NO}_{3}$ y $\mathrm{NH}_{4}$ tienen mayor con- centración en la parte inferior (Figura 3D, 3E y 3F). Este comportamiento de los compuestos nitrogenados suele indicar que el ambiente acuático está en proceso de eutrofización, como es el caso del lago Pomacochas (Chávez-Ortiz et al., 2014; Thompson et al., 2017).
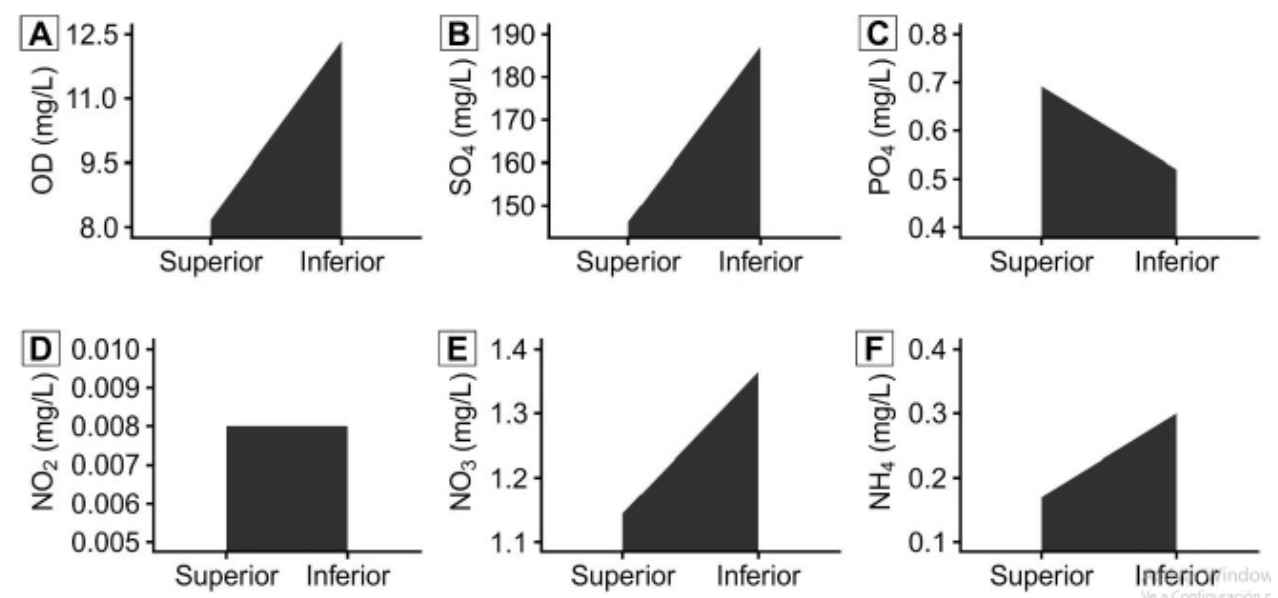

Figura 3. Gradientes fisicoquímicos generados en la columna de Winogradsky del lago Pomacochas. (A) OD, (B) $\mathrm{SO}_{4^{\prime}}$ (C) $\mathrm{PO}_{4^{\prime}}$ (D) $\mathrm{NO}_{2^{\prime}}$ (E) $\mathrm{NO}_{3^{\prime}}$ (F) $\mathrm{NH}_{4^{\prime}}$.

Los gradientes de $\mathrm{OD}$ y de $\mathrm{SO}_{4}$ en las columnas del río Pomacochas y la quebrada El Mito, son los que cabría esperar en columnas de Winogradsky en óptimas condiciones (Figura $4 \mathrm{~A}, 4 \mathrm{~B}, 5 \mathrm{~A}$ y $5 \mathrm{~B})$. Cabe destacar que, en ambos casos, la concentración de OD es bastante baja, indicando que la mayoría de las bacterias van a ser anoxigénicas (Yasa et al., 2006). $\mathrm{El} \mathrm{PO}_{4}$ y el $\mathrm{NO}_{3}$, tienen el mismo gradiente de concentración en ambas columnas (Figura 4C, 4E, 5C y 5E). Esto indica que hay un gran crecimiento de algas y cianobacterias en la parte superior, al ser estos nutrientes de estos organismos (Gonçalves et al., 2016). En cuanto a los gradientes de $\mathrm{NO}_{2}$ y $\mathrm{NH}_{4^{\prime}}$ presentan un comportamiento normal, al ser desechos de los microorganismos (Figuras 4D, 4F, 5D y 5F) (Leiva et al., 2017). Los resultados obtenidos fueron similares a los obtenidos en el río Hoosie en Estados Unidos (Rundell et al., 2014), y en el río Dniéper en Ucrania (Moshynets et al., 2013).
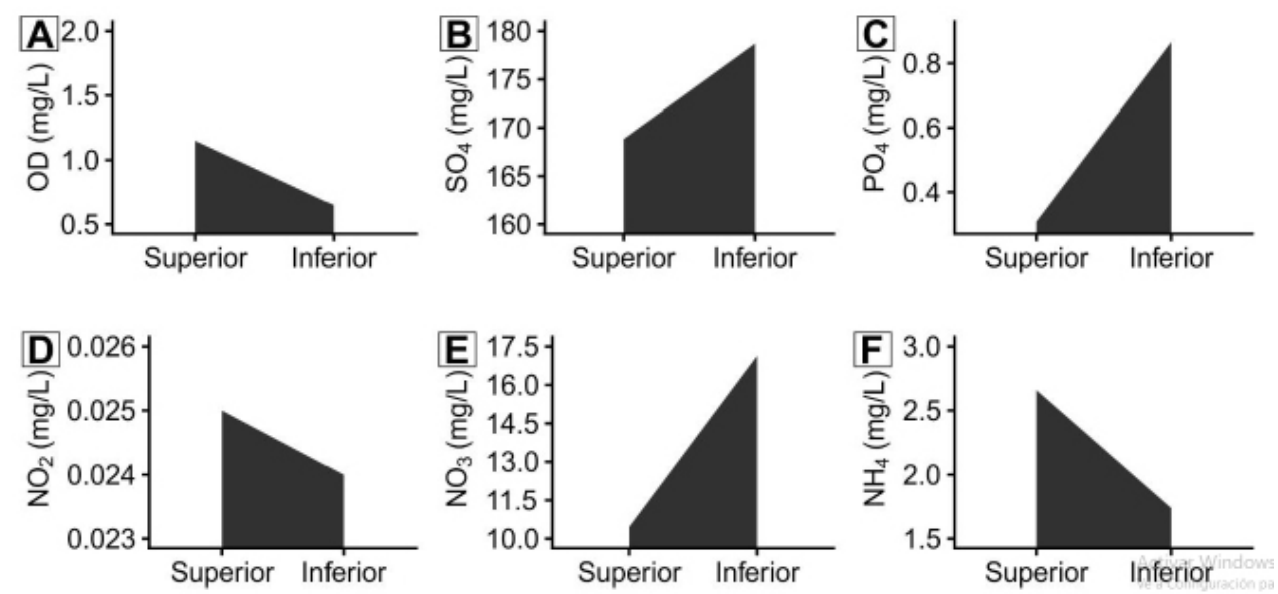

Figura 4. Gradientes fisicoquímicos generados en la columna de Winogradsky del río Pomacochas. (A) OD, (B) $\mathrm{SO}_{4^{\prime}}$ (C) $\mathrm{PO}_{4^{\prime}}$ (D) $\mathrm{NO}_{2^{\prime}}$ (E) $\mathrm{NO}_{3^{\prime}}$ (F) $\mathrm{NH}_{4^{\prime}}$. 

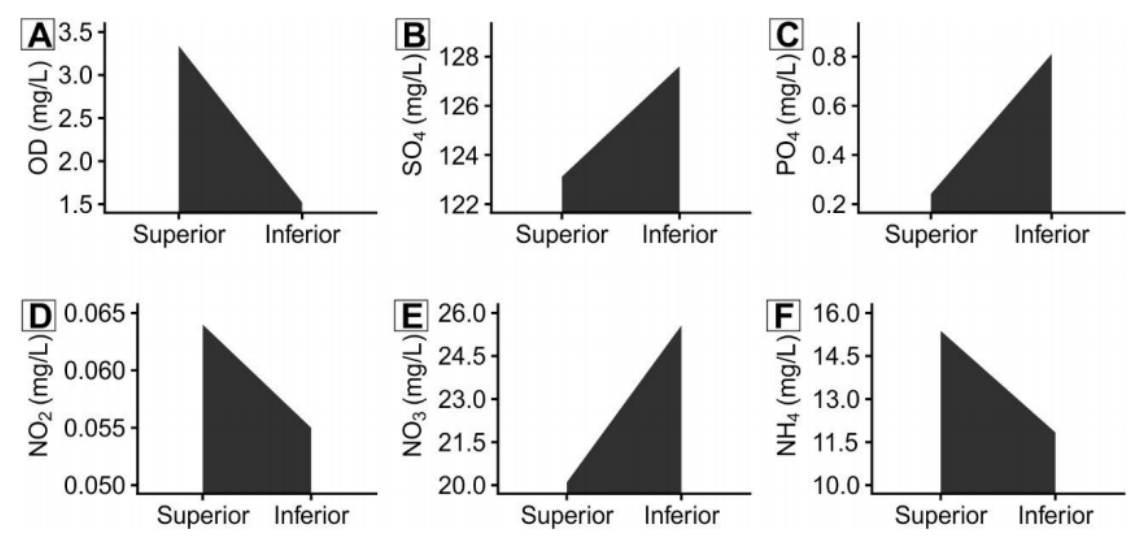

Figura 5. Gradientes fisicoquímicos generados en la columna de Winogradsky de la quebrada El Mito. (A) OD, (B) SO4, (C) PO4, (D) NO2, (E) NO3, (F) NH4.

\section{Comportamiento y relación de los am- bientes acuáticos y los parámetros fisico- químicos}

Los ecosistemas acuáticos estudiados y las columnas creadas se agruparon según sus características fisicoquímicas. Como se observa en la Figura 6, se forman tres conglomerados. Un primer conglomerado formado por las columnas del río Pomacochas y la quebrada El Mito; y un segundo formado por todos los ambientes acuáticos y un tercero formado por las columnas del lago Burlan y el lago Pomacochas. La formación del primer conglomerado es algo normal al provenir ambas columnas de sistemas lóticos, teniendo un mejor contenido de nutrientes, y al ser los únicos que presentaron el característico olor a huevos podridos (Sauterer, 2017). El segundo conglomerado tiene agrupados a todos los ecosistemas acuáticos, ya que no tienen los niveles de $\mathrm{SO}_{4}$ como en las columnas creadas al ser estas microcosmos controlados a nivel de laboratorio (Pagaling et al., 2017). En la agrupación del último conglomerado, el comportamiento de los gradientes de OD y $\mathrm{SO}_{4}$ es parecido. Estos resultados en los lagos son muy similares a los obtenidos en el lago Soda en la India (Bhatt et al., 2016).

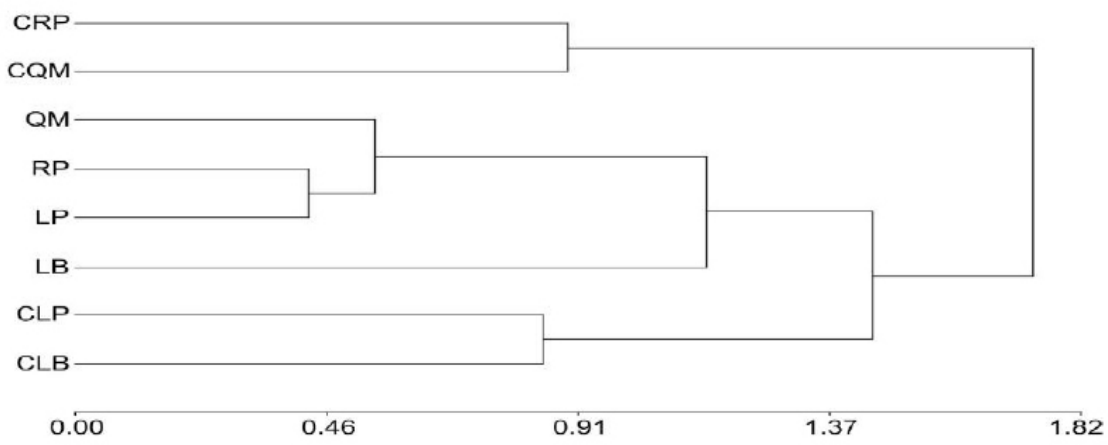

Figura 6. Conglomerados de los ecosistemas acuáticos y las columnas de Winogradsky.

Con respecto a cómo se relacionan los parámetros fisicoquímicos, en la figura 7 se pueden observar dos conglomerados. Un primer conglomerado donde solo están $\mathrm{SO}_{4}$ y $\mathrm{PO}_{4^{\prime}}$ y un segundo donde están los compuestos nitrogenados y el OD. La formación del primer conglomerado se debe a que las bacterias con pigmentos fotosintéticos, como las bacterias del azufre, necesitan del $\mathrm{PO}_{4}$ para poder desarrollarse (Madigan et al., 2019). Al mismo tiempo necesitan del $\mathrm{SO}_{4}$ como aceptor final de electrones al no haber oxígeno (Corrales et 
al., 2015). Así se genera el ambiente anoxigénico típico de las columnas de Winogradsky (Madigan et al., 2019). Por otro lado, el segundo conglomerado agrupa a los grupos nitro- genados y al OD, debido a la gran relación que tienen todos estos compuestos con el desarrollo de las algas y cianobacterias (Saltarelli et al., 2018).

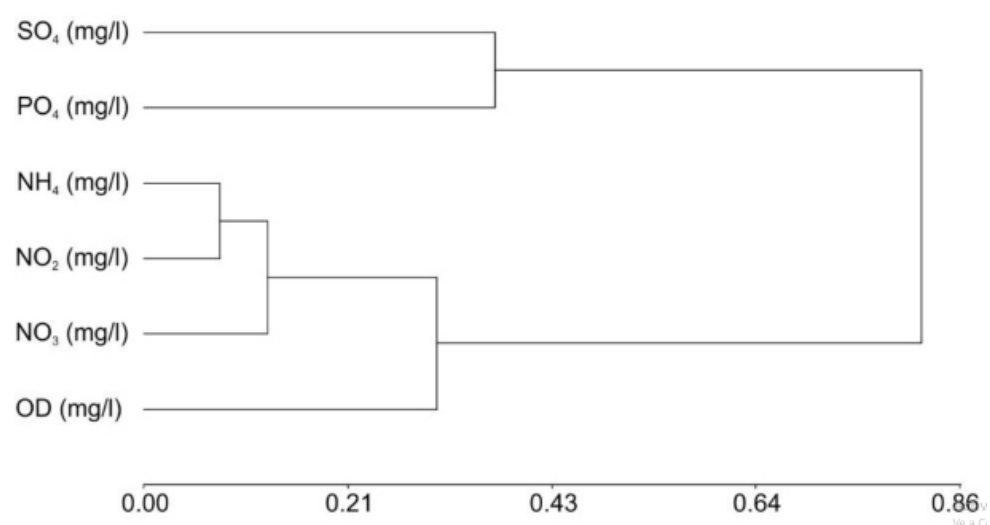

Figura 7. Conglomerados de los parámetros fisicoquímicos analizados en los cuatro ecosistemas acuáticos estudiados en la región Amazonas.

En cuanto al comportamiento de los parámetros fisicoquímicos en cada ecosistema y columna estudiada, según el análisis ANOVA, se vieron diferencias significativas en todos, menos en $\mathrm{PO}_{4}$
(Tabla 2). Este comportamiento se debe, principalmente, a que cada ambiente acuático es único, y por tanto el desarrollo del ciclo del azufre será diferente en cada uno ellos (Rogan et al., 2005).

Tabla 2. ANOVA de los parámetros fisicoquímicos analizados en los cuatro ecosistemas acuáticos estudiados en la Región Amazonas

\begin{tabular}{ccc}
\hline $\begin{array}{c}\text { Parámetro } \\
\text { Fisicoquímico }\end{array}$ & F & p-valor \\
\hline pH & 10.94 & $0.0015^{*}$ \\
$\mathrm{OD}$ & 14.84 & $0.0005^{*}$ \\
$\mathrm{CE}$ & 12020.78 & $<0.0001^{*}$ \\
$\mathrm{STD}$ & 12020.78 & $<0.0001^{*}$ \\
$\mathrm{NO}_{3}$ & 26.63 & $0.0001^{*}$ \\
$\mathrm{NO}_{2}$ & 80.92 & $<0.0001^{*}$ \\
$\mathrm{PO}_{4}$ & 2.66 & 0.0966 \\
$\mathrm{NH}_{4}$ & 52.43 & $<0.0001^{*}$ \\
$\mathrm{SO}_{4}$ & 89.21 & $<0.0001^{*}$ \\
\hline
\end{tabular}

Tipos de microorganismo en las columnas de Winogradsky

En las columnas de los ecosistemas lénticos, el gradiente de OD es inverso al normal, siendo la parte inferior la que más concentración de OD tiene. Este efecto en el gradiente se debe que las bacterias del azufre se han acumulado en la parte apical del sedimento, donde no hay oxígeno. Es probable que esta disposición se deba a que los lagos tienen las aguas en proceso de eutrofización (Chagnon et al., 2015). Por otro lado, las columnas de los ecosistemas lóticos se han desarrollado de la forma que cabría esperar. Esto significa que la mitad inferior de las columnas se encuentran en condiciones anoxigénicas, situándose en este sector las bacterias anaerobias. La mitad superior de las columnas tendrán condiciones oxigénicas, con sus respectivas bacterias aerobias. Finalmente, en el centro de la columna se situarán las bacterias microaerófilas o aerobias facultativas (Abbasian et al., 2015). 
Los diferentes estratos formados en todas las columnas se pueden observar en la Tabla 3. Hay que resaltar que en ninguna de las columnas se forman todos los estratos. Seguramente, esto se deba a la contamina- ción de los cuerpos de agua, relacionada con la agricultura y ganadería, afectando a microorganismos que participan en el ciclo del azufre (O'Neill y Davis 2012; Nogales et al., 2011).

Tabla 3. Estratos encontrados en las columnas de Winogradsky

\begin{tabular}{cc}
\hline Ecosistema acuático & Estratos \\
\hline & Gris blanquecino \\
Lago Burlan & Rojo \\
& Negro \\
& Verde oscuro \\
& Verde claro \\
& Rojo \\
Lago Pomacochas & Verde claro \\
& Verde oscuro \\
& Negro \\
Río Pomacochas & Blanco \\
& Rosa/Púrpura \\
Quebrada Mito & Negro \\
\hline
\end{tabular}

La columna del lago Burlan es en la que más estratos se desarrollaron. En la columna del lago Pomacochas los estratos encontrados fueron rojos y verdes. Por otro lado, en la columna del río Pomacochas se desarrollaron estratos de color rosa o púrpura y negro. Mientras que en la columna de la quebrada el Mito, solo se desarrolló un estrato de color negro. Cabe resaltar, que solo se detectó el típico olor a huevos podridos en las dos últimas columnas, por lo que se puede determinar la presencia de bacterias sulfatoreductoras en los ambientes lóticos (Corrales et al., 2015). El $\mathrm{CaSO}_{4}$ que se añadió a los sedimentos de cada columna es usado como sustrato por las bacterias sulfatoreductoras (Desulfovibrio), trasformando el $\mathrm{SO}_{4}^{2-}$ en $\mathrm{H}_{2} \mathrm{~S}$ (Singh, 2014). Al mismo tiempo, el $\mathrm{H}_{2} \mathrm{~S}$ producido es usado por las bacterias verdes del azufre (familia Clorobiaceas) reduciéndolo a $\mathrm{S}^{0}$. Este proceso también lo realizan las bacterias púrpuras del azufre (familia Cromatiaceas), pero en menor medida (Pibernat y Abella, 1993). El So producido sirve como sustrato en las bacterias sulfooxidantes (Thiobacillus), para transformarlo de nuevo en $\mathrm{SO}_{4}{ }^{2-}$, cerrando así el ciclo del azufre. Por tanto, las bacterias más profundas serían las sulfatoreductoras, encima de las cuales estarían las verdes del azufre, seguidas de las púrpuras del azufre, para terminar, en la parte más apical, con las sulfatooxidantes (Colturato et al., 2016). Normalmente, las bacterias verdes del azufre se sitúan debajo de las púrpuras del azufre, al ser menos tolerantes al oxígeno y más tolerantes al $\mathrm{H}_{2} \mathrm{~S}$ que producen las sulfatoreductoras, de ahí esta disposición en la columna (Huh et al., 2014). Otro factor a tener en cuanta, es la disminución del pH por la liberación de protones durante la trasformación del $\mathrm{H}_{2} \mathrm{~S}$ a $\mathrm{S}^{0}$ por parte de las bacterias verdes del azufre. Es por ello que se añade $\mathrm{CaCO}_{3}$ como agente tamponador (Moreno et al., 2012). En lo referente a la parte apical de la columna de agua, en la zona aeróbica se forma un biofilm, compuesto principalmente por algas y cianobacterias. Estas desprenden oxígeno constantemente, manteniendo el gradiente de OD en la columna (Rundell et al., 2014). Por último, en la parte inferior donde se acumula la materia orgánica 
y se dan las condiciones de anaerobiosis total, se localizan las bacterias heterótrofas anaeróbicas, como Clostridium (Gomes y Dos Santos, 2011).

\section{CONCLUSIONES}

Los ecosistemas lénticos estudiados, el lago Burlan y el lago Pomacochas, tiene sus aguas en proceso de eutrofización debido a los desechos generados por la agricultura del arroz y la ganadería que se da respectivamente en cada zona. En cuanto a los ecosistemas lóticos, el río Pomacochas se ve afectado por la contaminación ganadera propia de la zona. Por otra parte,la quebrada El Mito se ve afectada por desechos surgidos de la producción cafetalera. En todos los ecosistemas estudiados, el ciclo del azufre se ha visto afectado por las actividades antrópicas. Tanto el río Pomacochas como la quebrada El Mito son los que tiene más afectado el ciclo del azufre, al desarrollar menos estratos en sus respectivas columnas.

Se recomienda seguir estudiando estos ambientes acuáticos y su relación con el ciclo del azufre, para ver que parte del ciclo se está viendo afectado y determinar las posibles causas.

\section{Agradecimientos}

Los autores agradecen el apoyo de Damaris Leiva Tafur y Christian Ricardo Calle Yunis, por su ayuda en la recolección de muestras y la elaboración de las columnas de Winogradsky. También agradecen el apoyo mostrado por Instituto de Investigación para el Desarrollo Sustentable de Ceja de Selva (INDES-CES) de la Universidad Nacional Toribio Rodríguez de Amazonas (UNTRM).

\section{REFERENCIAS BIBLIOGRÁFICAS}

Abbasian, F., Lockington, R., Mallavarapu, M., \& Naidu, R. (2015). A pyrosequencing-based analysis of microbial diversity governed by ecological conditions in the Winogradsky column. World Journal of Microbiology and Biotechnology, 31(7), 1115-1126. https://doi. org/10.1007/s11274-015-1861-y
Alva-Cruz, R. R. (2010). Zonificación Ecológica y Económica del Departamento de Amazonas: Evaluación de recursos turísticos. Informe temático. Iquitos, Perú. https://doi.org/10.1017/ CBO9781107415324.004

ANA (Autoridad Nacional del Agua). (2016). Protocolo Nacional para el Monitoreo de la Calidad de los Recursos Hídricos Superficiales. Lima, Perú: Autoridad Nacional del Agua.

Anderson, D. C., \& Hariston, R. V. (1999). The Winogradsky Column \& Biofilms: Models for Teaching Nutrient Cycling \& Succession in an Ecosystem. The American Biology Teacher, 61 (6), 453-459. https://doi.org/10.2307/4450728 APHA, AWWA, \& WEF. (2017). Standard Methods for the Examination of Water and Wastewater. (R. B. Baird, A. D. Eaton, \& E. W. Rice, Eds.). Washington DC: American Public Health Association/American Water Works Association/ Water Environment Federation.

Babcsányi, I., Meite, F., \& Imfeld, G. (2017). Biogeochemical gradients and microbial communities in Winogradsky columns established with polluted wetland sediments. FEMS Microbiology Ecology, 93(8). https://doi. org/10.1093/femsec/fix089

Bacchetti De Gregoris, T., Barroeta, B., \& Nuñez, A. E. (2015). La columna bioelectrogénica: una herramienta para introducir conceptos de ecología microbiana y electroquímica en la educación secundaria. Revista Eureka Sobre Enseñanza y Divulgación de Las Ciencias, 12(3), 529-535.

Benoit, T. G. (2015). Increase the visibility of microbial growth in a winogradsky column by substituting diatomaceous Earth for sediment. Journal of Microbiology \& Biology Education, 16(1), 85-86. https://doi.org/10.1128/ jmbe.v16i1.889

Bhatt, H. H., Sharma, B. M., \& Upasani, V. N. (2016). Studies on Microbial Diversity of a 
Soda Lake in India by Winogradsky Column Technique. International Journal of Current Microbiology and Applied Sciences, 5(4), 608-614.

Blaber, S. J. M., \& Barletta, M. (2016). A review of estuarine fish research in South America: what has been achieved and what is the future for sustainability and conservation? Journal of Fish Biology, 89(1), 537-568. https://doi. org/10.1111/jfb.12875

Bucher, E. H., \& Abril, A. B. (2006). Limnologia Biologica. In E. H. Bucher (Ed.), Bañados del río Dulce y Laguna Mar Chiquita (Córdoba, Argentina) (Vol. 7, pp. 117-137). Cordoba, Argentina: Academia Nacional de Ciencias.

Chagnon, M., Kreutzweiser, D., Mitchell, E. A. D., Morrissey, C. A., Noome, D. A., \& Van der Sluijs, J. P. (2015). Risks of large-scale use of systemic insecticides to ecosystem functioning and services. Environmental Science and Pollution Research International, 22(1), 119-134. https:// doi.org/10.1007/s11356-014-3277-x

Chávez-Ortiz, J., Leiva-Tafur, D., Rascón, J., Hoyos, I., \& Corroto, F. (2014). Estado trófico del lago Pomacochas a través de parámetros fisicoquímicos y bacteriológicos. Revista Indes, 2(2), 70-78.

Colturato, L. F. D. B., Faria, J. P. de O., Motta, V. S., Santos, L. L. dos, \& Chernicharo, C. A. de L. (2016). Avaliação de lavador de gases do tipo Venturi, operando com solução de hidróxido de sódio, para dessulfuração de biogás com altas concentrações de H2S. Engenharia Sanitaria e Ambiental, 21(1), 65-76. https://doi. org/10.1590/S1413-41520201600100131751

Corrales, L., Antolinez, D., Bohórquez, J., \& Corredor, A. (2015). Bacterias anaerobias: procesos que realizan y contribuyen a la sostenibilidad de la vida en el planeta. Nova, 13 (23), 55-81.

Freedman, B. (2018). Environmental science. Halifax, Canada: Dalhousie University Libra- ries Digital Editions. https://doi.org/10.31729/ jnma. 1240

Galván, L. A., \& Rios, L. A. (2013). Procesos, bacterias y arqueobacterias involucrados en el ciclo biológico del nitrógeno para la eliminación de compuestos nitrogenados en ecosistemas de agua dulce, una revisión sistemática. Hechos Microbiológicos, 4(1), 34-51.

Giraldo, M. (2012). Aislamiento y caracterización de microalgas formadoras de tapetes microbianos asociados a un cultivo hidropónico de plantas halófitas. Universidad de Las Palmas de Gran Canaria.

Goldemberg, J., Coelho, S. T., \& Guardabassi, P. (2008). The sustainability of ethanol production from sugarcane. Energy Policy, 36(6), 2086-2097. https://doi.org/10.1016/j.enpol.2008.02.028

Gomes, A., \& Dos Santos, L. (2011). Utilização da Coluna de Winogradsky para a Demonstração do Efeito dos Metais Pesados na Microbiota Oxidante de Enxofre em Ambientes Aquáticos: Uma Abordagem Experimental. Cadernos UniFOA, 16(8), 89-94.

Gonçalves, A. L., Pires, J. C. M., \& Simões, M. (2016). Wastewater polishing by consortia of Chlorella vulgaris and activated sludge native bacteria. Journal of Cleaner Production, 133, 348-357. https://doi.org/10.1016/j.jclepro.2016.05.109

Grau, R. R., Limansky, A. S., Diaz Ricci, J. C., \& De Mendoza, D. (1991). The windogradsky column: A simple and inexpensive approach to teach environmental biochemistry. Biochemical Education, 19(3), 143-147. https://doi. org/10.1016/0307-4412(91)90058-G

Gutierrez, A. V., Terrazas, L. E., \& Álvarez, M. T. (2007). Aislamiento y cultivo de bacterias sulfato reductoras acidófilas para la Producción de Sulfuro Biogénico para la precipitación de metales pesados. BIOFARBO, 15, 5-12. 
Huh, J., Saikin, S. K., Brookes, J. C., Valleau, S., Fujita, T., \& Aspuru-Guzik, A. (2014). Atomistic study of energy funneling in the light-harvesting complex of green sulfur bacteria. Journal of the American Chemical Society, 136(5), 20482057. https://doi.org/10.1021/ja412035q

Jimenez-Montealegre, R., Zamora-Castro, J., \& Zuniga-Calero, G. (2015). Determinacion del flujo de agua para la biorremediacion en sistemas recirculados acuaculturales utilizando tapetes microbianos construidos. Latin American Journal of Aquatic Research, 43(1), 234-247. https://doi.org/10.3856/vol43-issue1-fulltext-20

Karlov, D. S., Marie, D., Sumbatyan, D. A., Chuvochina, M. S., Kulichevskaya, I. S., Alekhina, I. A., \& Bulat, S. A. (2017). Microbial communities within the water column of freshwater Lake Radok, East Antarctica: predominant 165 rDNA phylotypes and bacterial cultures. Polar Biology, 40(4), 823-836. https://doi.org/10.1007/s00300016-2008-9

Kolpin, D. W., Furlong, E. T., Meyer, M. T., Thurman, E. M., Zaugg, S. D., Barber, L. B., \& Buxton, H. T. (2002). Pharmaceuticals, hormones, and other organic wastewater contaminants in U.S. streams, 1999-2000: A national reconnaissance. Environmental Science and Technology, 36(6), 1202-1211. https://doi.org/10.1021/ es011055j

Leiva, A., Moreira, D. W., Andrade, J. A., Aveiga, A. M., \& Loureiro, J. A. (2017). Nitrificación En La Estabilización De Residuos Líquidos En Un Reactor Batch Aireado Completamente Mezclado. European Scientific Journal, 13(3), 438-446. https://doi.org/10.19044/esj.2016. v13n3p438

López-Pérez, J. P., \& Boronat-Gil, R. (2019). Contribución de los microorganismos en la génesis de los minerales del azufre y su ciclo biogeoquímico. Estudio en un laboratorio de educación secundaria. Enseñanza de Las Ciencias de La Tierra, 27(2), 192-199.

Madigan, M. T., Bender, K. S., Buckley, D. H., Sattley, W. M., \& Stahl, D. A. (2019). Brock Biology of Microorganisms (15th ed.). New York, EEUU: Pearson Education Limited.

Martínez, G. (2013). Diversidad microbiana, detección e identificación de cianobacterias tóxicas paleo-sedimentos de la Laguna Blanca a través de métodos moleculares. Universidad de la República, Urugay.

Moreno, R., Gorriti, M., Flores, M., \& Albarracín, V. (2012). Microbiología ambiental y ecología microbiana en el estudio de microorganismos en ambientes extremos. Reduca (Biología). Serie Microbiología, 5(5), 94-109.

Moshynets, O., Boretska, M., \& Spiers, A. J. (2013). From winogradsky's column to contemporary research using bacterial microcosms. In C. C. Harris (Ed.), Microcosms: Ecology, Biological Implications and Environmental Impact (pp. 1-27). London, United Kingdom: Nova Science Publishers, Inc.

Nicoletti, G., Arcuri, N., Nicoletti, G., \& Bruno, R. (2015). A technical and environmental comparison between hydrogen and some fossil fuels. Energy Conversion and Management, 89, 205-213. https://doi.org/10.1016/j.enconman.2014.09.057

Nogales, B., Lanfranconi, M. P., Piña-Villalonga, J. M., \& Bosch, R. (2011). Anthropogenic perturbations in marine microbial communities. FEMS Microbiology Reviews, 35(2), 275-298. https://doi.org/10.1111/j.15746976.2010.00248.x

Núñez-cardona, M. T. (2003). Aislamiento y caracterización pigmentaria de las bacterias rojas del azufre de la laguna de Tampamachoco, Veracruz Isolation and pigment characte- 
rization of purple sulphur bacteria from Tampamachoco lagoon, Veracruz. Hidrobiológica, 13(3), 171-176.

O'Neill, S. W., \& Davis, A. P. (2012). Water Treatment Residual as a Bioretention Amendment for Phosphorus. II: Long-Term Column Studies. Journal of Environmental Engineering, 138(3), 328-336. https://doi.org/10.1061/ (ASCE)EE.1943-7870.0000436

Oliva, M., Rojas, D., Morales, A., Oliva, C., \& Oliva, M. A. (2015). Contenido nutricional, digestibilidad y rendimiento de biomasa de pastos nativos que predominan en las cuencas ganaderas de Molinopampa, Pomacochas y Leymebamba, Amazonas, Perú. Scientia Agropecuaria, 6(3), 211-215. https://doi.org/10.17268/sci.agropecu.2015.03.07

Pagaling, E., Strathdee, F., Spears, B. M., Cates, M. E., Allen, R. J., \& Free, A. (2014). Community history affects the predictability of microbial ecosystem development. The ISME Journal, 8(1), 19-30. https://doi.org/10.1038/ ismej.2013.150

Pagaling, E., Vassileva, K., Mills, C. G., Bush, T., Blythe, R. A., Schwarz-Linek, J., ... Free, A. (2017). Assembly of microbial communities in replicate nutrient-cycling model ecosystems follows divergent trajectories, leading to alternate stable states. Environmental Microbiology, 19(8), 3374-3386. https://doi. org/10.1111/1462-2920.13849

Picazo, A., Rochera, C., Vicente, E., Miracle, M. R., \& Camacho, A. (2013). Spectrophotometric methods for the determination of photosynthetic pigments in stratified lakes: a critical analysis based on comparisons with HPLC determinations in a model lake. Limnetica, 32(1), 139-158.

R Core Team. (2020). R: A Language and Environment for Statistical Computing. R Founda- tion for Statistical Computing, Vienna, Austria. Retrieved from https://www.r-project.org/

Rogan, B., Lemke, M., Levandowsky, M., \& Gorrell, T. (2005). Exploring the Sulfur Nutrient Cycle Using the Winogradsky Column. The American Biology Teacher, 67(6), 348-356. https://doi.org/10.1662/0002-7685(2005)067[0 348:ETSNCU]2.0.CO;2

Sacaca, S. I. (2006). Distribución de bacterias Sufato Reductoras en sedimentos de lagunas y turberas de la cuenca Milluni Cordillera Real, La Paz-Bolivia. Universidad Mayor de San Andres.

Saltarelli, W. A., Dodds, W. K., Tromboni, F., Calijuri, M. C., Neres-lima, V., Jordão, C. E., \& Cunha, D. G. F. (2018). Variation of stream metabolism along a tropical environmental gradient. Journal of Limnology, in press. https:// doi.org/10.4081/jlimnol.2018.

Sánchez-Vasquez, R. P. (2018). Estrategias para el posicionamiento de la laguna de Burlan como parte de la oferta turística en la Provincia de Utcubamba - 2018. Universidad Nacional Toribio Rodríguez de Mendoza de Amazonas.

Sauterer, R. (2017). Experiences Using Ecosystem Microcosms. The American Biology Teacher, 79(6), 466-472.

SENAMHI (Servicio Nacional de Meteorología e Hidrología del Perú). (2020). Servicio Nacional de Meteorología e Hidrología del Perú. Lima, Perú. Retrieved from http://www.senamhi.gob.pe

Singh, K. P. (2014). Biogeophysical signatures of microbial natural gas accumulation. Current Science, 107(11), 1880-1884.

Uchimiya, M., \& Stone, A. T. (2009). Reversible redox chemistry of quinones: Impact on biogeochemical cycles. Chemosphere, 77(4), 451-458. https://doi.org/10.1016/j.chemosphere.2009.07.025 
Wetzel, R. G. (2001). Limnology: Lake and River Ecosystems (Tercera Ed). San Diego, USA: Academic Press Elservier.

Yasa, I., Cadirci, B., Kocyigit, A., \& Öztürk, T. (2006). Enrichment and isolation of anoxygenic phototrophic bacteria in Winogradsky Column. EU Journal of Fisheres \& Aquatic Science, 23, 71-73.

Zakharenko, A. S., Pimenov, N. V., Ivanova, V. G., \& Zemskaya, T. I. (2015). Detection of methane in the water column at gas and oil seep sites in central and southern Lake Baikal. Microbiology, 84(1), 90-97. https://doi.org/10.1134/ S0026261715010178

Zamparas, M., \& Zacharias, I. (2014). Restoration of eutrophic freshwater by managing internal nutrient loads. A review. Science of the Total Environment, 496, 551-562. https://doi. org/10.1016/j.scitotenv.2014.07.076

\section{CORRESPONENCIA: \\ MsC. Jesús Rascón Barrios}

jesus.rascon@untrm.edu.pe 